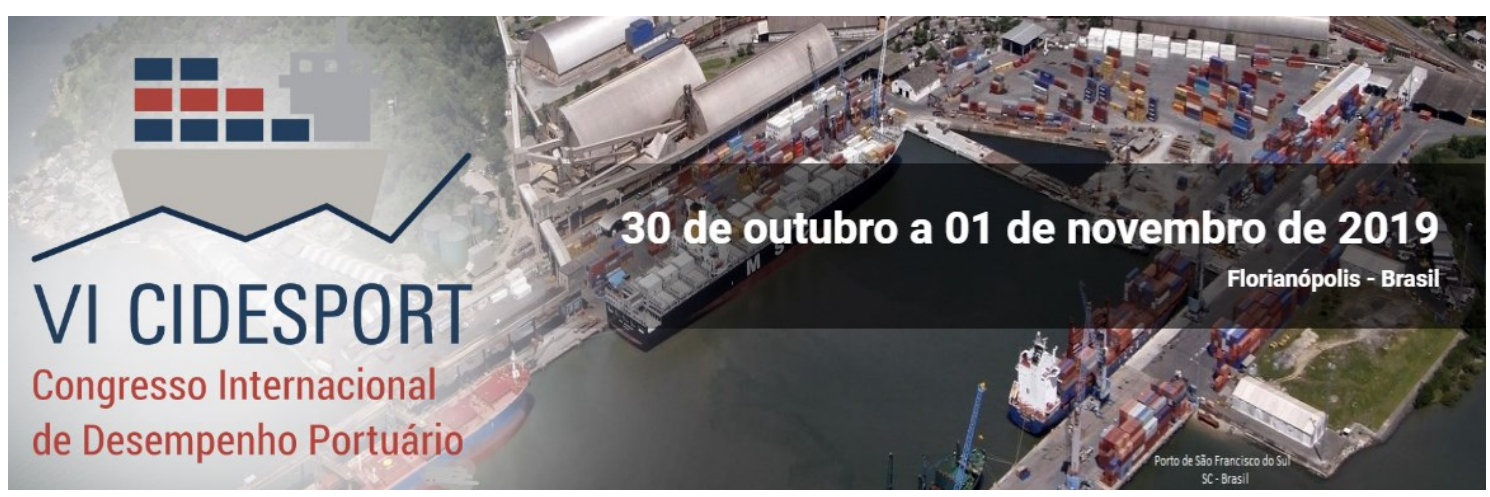

\title{
A EXPERIÊNCIA DO DEPARTAMENTO NACIONAL DE INFRAESTRUTURA DE TRANSPORTES - DNIT, NA CONTRATAÇÃO DAS INSTALAÇÕES PORTUÁRIAS PÚBLICAS DE PEQUENO PORTE - IP4
}

\author{
Rafael Gerard Demuelenaere \\ Departamento Nacional de Infraestrutura de Transportes \\ Nathalia Prado Radel \\ Departamento Nacional de Infraestrutura de Transportes
}

Resumo: Criadas pela Lei $n^{0} 12.815 / 2013$, as Instalações Portuárias Públicas de Pequeno Porte - IP4 têm que satisfazer requisitos de eficiência, segurança, atendimento ao interesse público, generalidade, conforto, cortesia na prestação dos serviços, e preservação do meio ambiente. O DNIT, por meio de suas Administrações Hidroviárias - $\mathrm{AH}$, atua em cada IP4 para garantir o funcionamento de todo o empreendimento: retroporto - facilidades localizadas em terra - e estruturas de acostagem, adequadas às características de cada rio. Para cumprir sua missão de construção, manutenção e operação das IP4, a legislação atual permite ao DNIT a execução indireta, ou seja, o órgão ou entidade contrata com terceiros por meio de licitação. O objetivo geral deste trabalho é analisar as contratações de serviços e obras referente as Instalações Portuárias Públicas de Pequeno Porte - IP4 feitas pelo DNIT. Dentre os objetivos específicos destacam-se a avaliação acerca dos benefícios da escolha da modalidade licitatória, bem como qual obteve maior êxito na contratação sob o viés da isonomia, vantajosidade e promoção do desenvolvimento nacional sustentável. Com o resultado das análises verificou-se que a modalidade Pregão Eletrônico, demonstrou vantagens em detrimento das outras modalidades analisadas - Regime Diferenciado de Contratações Públicas - RDC e Tomada de Preço.

Palavras-chave: DNIT. IP4. Contratação. Modalidades. Pregão Eletrônico.

\section{INTRODUÇÃO}

O Brasil possui milhares de quilômetros de costas marítimas com potencial de melhor aproveitamento. Considerando esta posição de destaque e imprescindibilidade da estrutura portuária o governo federal instituiu no ano de 2013 o novo marco regulatório do Setor Portuário Nacional, com a edição da Lei no 12.815 , de 5 de junho de 2013, assim como de seu regulamento, o Decreto $n^{\circ} 8.033$, de 27 de junho de 2013. (Fernandes, 2016)

Criadas pela Lei $n^{0} 12.815 / 2013$, as Instalações Portuárias Públicas de Pequeno Porte - IP4 têm que satisfazer requisitos de eficiência, segurança,

\footnotetext{
* A revisão gramatical, ortográfica, ABNT ou APA foi realizada pelos autores.
} 
atendimento ao interesse público, generalidade, conforto, cortesia na prestação dos serviços, e preservação do meio ambiente. Além disso, precisam constar no Sistema Nacional de Viação - SNV, operar exclusivamente com embarcações de navegação interior e estar fora da poligonal do porto organizado. Conforme inciso $\mathrm{VI}$, art. $2^{\circ}$ da lei 12.815 considera-se:

VI - instalação portuária pública de pequeno porte: instalação portuária explorada mediante autorização, localizada fora do porto organizado e utilizada em movimentação de passageiros ou mercadorias em embarcações de navegação interior;

O Departamento Nacional de Infraestrutura de Transportes - DNIT é o responsável pela construção, manutenção e operação das IP4. Um dos objetivos é prover municípios localizados às margens dos rios, que dependem exclusivamente do transporte hidroviário, de instalações que fornecessem segurança nas operações de embarque e desembarque de passageiros e insumos como medicamentos, gêneros alimentícios, vestuários, entre outros.

O DNIT, por meio de suas Administrações Hidroviárias - AH, atua em cada IP4 para garantir o funcionamento de todo o empreendimento: retroporto - facilidades localizadas em terra - e estruturas de acostagem, adequadas às características de cada rio.

Estas Instalações trazem diversos benefícios para a população, dentre eles:

-Assegura o embarque e desembarque, com segurança, de passageiros e cargas, independentemente dos regimes hídricos;

-Gera empregos na construção, operação e manutenção das IP4 dentro da região;

-Possibilita o fornecimento de alimentos, bens e serviços em geral;

-Reduz as perdas da produção agrícola e do pescado ao disponibilizar fábrica de gelo, armazém de carga e agilizar o transporte;

-Reduz os custos logísticos de transporte fluvial, para empresas de navegação e usuários ribeirinhos. (Moreira, 2018)

Para cumprir sua missão de construção, manutenção e operação das IP4, a legislação atual permite ao DNIT a execução indireta, ou seja, o órgão ou entidade contrata com terceiros por meio de licitação.

O objetivo geral deste trabalho é analisar as contratações de serviços e obras referente as Instalações Portuárias Públicas de Pequeno Porte - IP4 feitas pelo DNIT.

Dentre os objetivos específicos destacam-se a avaliação acerca dos benefícios da escolha da modalidade licitatória, bem como qual obteve maior êxito na contratação sob o viés da isonomia, vantajosidade e promoção do desenvolvimento nacional sustentável.

\section{REFERENCIAL TEÓRICO}

\subsection{Departamento Nacional de Infraestrutura de Transportes - DNIT}

O DNIT possui como objetivo, implantar políticas para administração da infraestrutura do Sistema Federal de Viação, que é constituído pelas instalações portuárias. Vejamos o preconizado nos dispositivos abaixo, da Lei n $n^{\circ} 10.233$ de 05 de junho de 2001: 


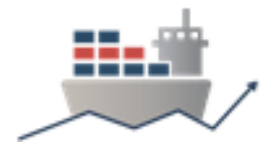

"Art. 80. Constitui objetivo do DNIT implementar, em sua esfera de atuação, a política formulada para a administração da infraestrutura do Sistema Federal de Viação, compreendendo sua operação, manutenção, restauração ou reposição, adequação de capacidade, e ampliação mediante construção de novas vias e terminais, segundo os princípios e diretrizes estabelecidos nesta Lei.

Art. 81. A esfera de atuação do DNIT corresponde à infraestrutura do Sistema Federal de Viação, sob a jurisdição do Ministério da Infraestrutura, constituída de:

I - vias navegáveis, inclusive eclusas ou outros dispositivos de transposição hidroviária de níveis;

(...)

V - instalações portuárias;

Art. 82. São atribuições do DNT, em sua esfera de atuação:

(...)

IV - administrar, diretamente ou por meio de convênios de delegação ou cooperação, os programas de operação, manutenção, conservação, restauração e reposição de rodovias, ferrovias, vias navegáveis, terminais e instalações portuárias;

$\mathrm{V}$ - gerenciar, diretamente ou por meio de convênios de delegação ou cooperação, projetos e obras de construção e ampliação de rodovias, ferrovias, vias navegáveis, terminais e instalações portuárias, decorrentes de investimentos programados pelo Ministério dos Transportes e autorizados pelo Orçamento Geral da União;"

O DNIT representado pela Diretoria de Infraestrutura Aquaviária - DAQ é responsável por atuar na malha hidroviária constante no Sistema Nacional de Viação - SNV (Lei n. 12.379/2011), bem como pela gestão, manutenção, ampliação, modernização, construção, fiscalização, e elaboração de estudos técnicos das hidrovias, portos interiores e eclusas.

As ações e políticas implementadas nas hidrovias administradas pela DAQ têm por finalidade aumentar o escoamento de commodities, diminuir o custo do transporte de cargas, aumentar segurança e, também, garantir melhores condições de atracação para embarcações de pequeno porte e transporte de passageiros.

Para executar as suas ações e tornar a gestão mais eficiente, a DAQ conta com 08 Administrações Hidroviárias, que exercem por delegação, as atribuições operacionais estabelecidas pelo Regimento Interno do DNIT para suas unidades regionais. São elas: AHIMOC, AHIMOR, AHINOR, AHITAR, AHSFRA, AHIPAR, AHRANA e AHSUL.

As principais atribuições das AH's são: a coordenação de estudos, planos, programas, projetos, obras e serviços, incluídos os de meio ambiente, visando a construção, a manutenção, a conservação, a restauração e a operação da infraestrutura aquaviária e a revisão de projetos de engenharia na fase de execução de obras. (Moreira, 2018). A figura 01 mostra a área de atuação de cada Administração Hidroviária do DNIT. 
VI CIDESPORT/2019

Congresso Internacional

de Desempenho Portuário
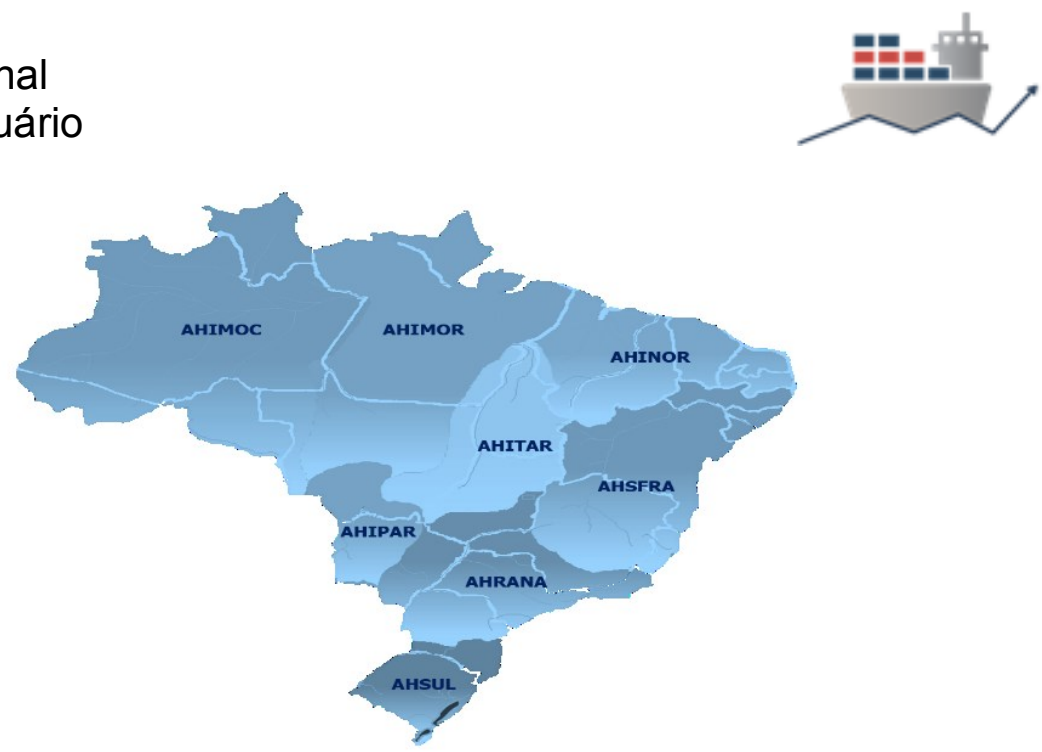

Figura 01: Administrações Hidroviárias do DNIT. Fonte: https://www.dnit.gov.br/modais-2/aquaviario/administracoes-hidroviarias

Além disso, a autarquia, atua em um sistema que conta com 44 Instalações Portuárias Públicas de Pequeno Porte - IP4 concluídas, 13 IP4 em construção e 8 eclusas nos Estados do Amazonas, Pará, Rondônia e Roraima conforme mostra a figura 02.

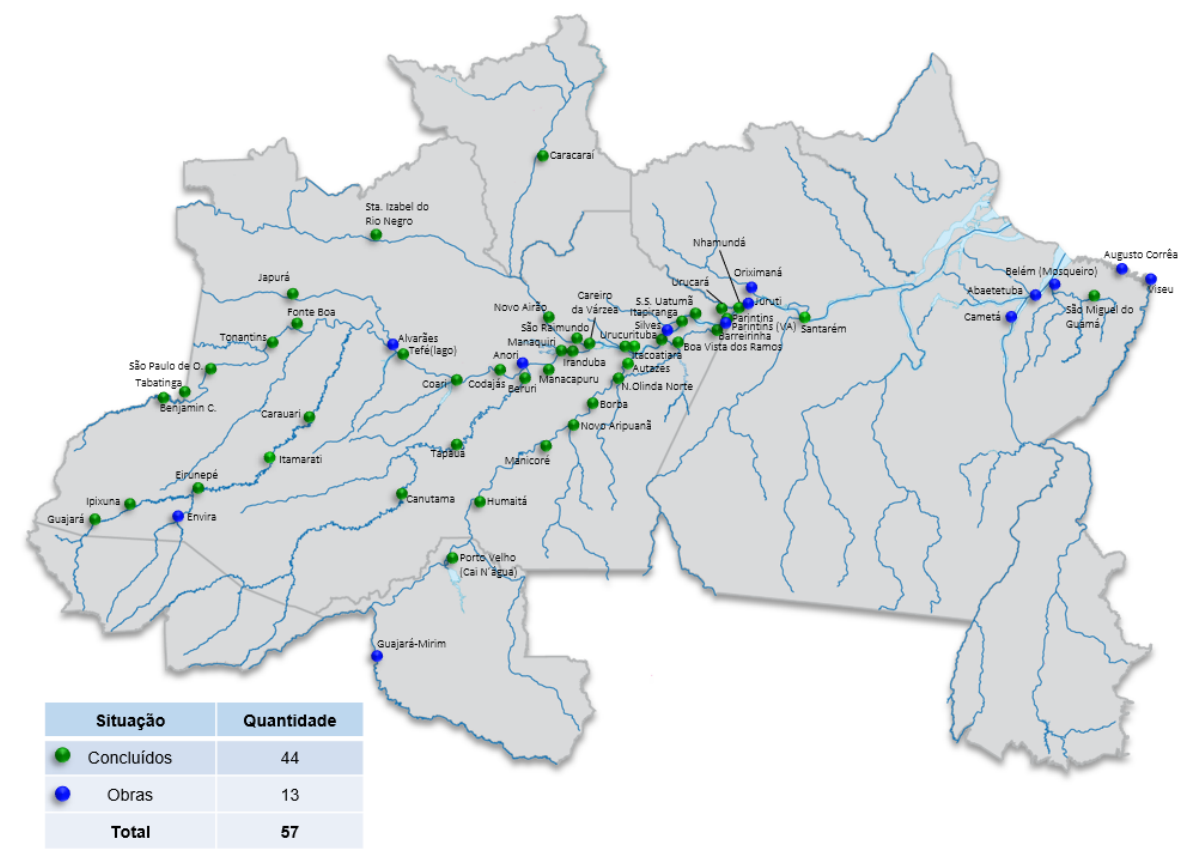

Figura 02: Instalações Portuárias Públicas de Pequeno Porte - IP4. Fonte: https://www.dnit.gov.br/modais-2/aquaviario/ip4

Conforme Medida Provisória $n^{\circ} 882$, de 3 de maio de 2019, as atribuições do Departamento de Infraestrutura Portuária e Gestão Ambiental - DIPGA da extinta Secretaria Nacional de Portos foram incorporadas ao DNIT. Com isso, o DNIT passa a ser responsável por projetar, acompanhar e executar, direta ou indiretamente, obras ou serviços de engenharia em portos organizados, decorrentes de investimentos programados pelo Ministério da Infraestrutura e autorizados pelo Orçamento Geral da União.

\subsection{Legislação}


As obras e serviços da Administração Pública, quando contratadas com terceiros, serão necessariamente precedidas de licitação, podendo para isso utilizar os seguintes normativos: a lei $8.666 / 1993$ para contratação de obras, a lei 10.520/2002 quando envolver aquisição de bens e serviços comuns de engenharia e a lei 12.462/2011, quando se tratar das ações integrantes do programa de aceleração do crescimento (PAC).

\subsubsection{Lei 8.666/93}

Regulamenta o art. 37, inciso XXI, da Constituição Federal, institui normas para licitações e contratos da Administração Pública e dá outras providências. Esta Lei estabelece normas gerais sobre licitações e contratos administrativos pertinentes a obras, serviços, inclusive de publicidade, compras, alienações e locações no âmbito dos Poderes da União, dos Estados, do Distrito Federal e dos Municípios. Vejamos o previsto nos artigos:

Art. $2^{\circ}$ As obras, serviços, inclusive de publicidade, compras, alienações, concessões, permissões e locações da Administração Pública, quando contratadas com terceiros, serão necessariamente precedidas de licitação, ressalvadas as hipóteses previstas nesta Lei.

(...)

Art. $6^{\circ}$ Para os fins desta Lei, considera-se:

I - Obra - toda construção, reforma, fabricação, recuperação ou ampliação, realizada por execução direta ou indireta;

II - Serviço - toda atividade destinada a obter determinada utilidade de interesse para a Administração, tais como: demolição, conserto, instalação, montagem, operação, conservação, reparação, adaptação, manutenção, transporte, locação de bens, publicidade, seguro ou trabalhos técnico-profissionais;

(...)

Art. 22 São modalidades de licitação:

I - concorrência;

II - tomada de preços;

III - convite;

IV - concurso; e

$\mathrm{V}$ - leilão.

(...)

$\S 2^{\circ}$ Tomada de preços é a modalidade de licitação entre interessados devidamente cadastrados ou que atenderem a todas as condições exigidas para cadastramento até o terceiro dia anterior à data do recebimento das propostas, observada a necessária qualificação.

\subsubsection{Lei $10.520 / 2002$}

Institui, no âmbito da União, Estados, Distrito Federal e Municípios, nos termos do art. 37, inciso XXI, da Constituição Federal, modalidade de licitação denominada pregão, para aquisição de bens e serviços comuns, e dá outras providências. $O$ parágrafo único da Lei $n^{\circ} 10.520 / 2002$ estabelece o que é considerado como serviço comum, vejamos:

Art. $1^{\circ}$ Para aquisição de bens e serviços comuns, poderá ser adotada a licitação na modalidade de pregão, que será regida por esta Lei. 
Parágrafo único. Consideram-se bens e serviços comuns, para os fins e efeitos deste artigo, aqueles cujos padrões de desempenho e qualidade possam ser objetivamente definidos pelo edital, por meio de especificações usuais no mercado.

Importante ressaltar, que quando da utilização da modalidade pregão, o critério de julgamento adotado deverá ser o menor preço, conforme estabelecido no artigo $4^{\circ}$, $\mathrm{X}$, in litteris:

Art. $4^{\circ} \mathrm{A}$ fase externa do pregão será iniciada com a convocação dos interessados e observará as seguintes regras:

$(\ldots)$

X - para julgamento e classificação das propostas, será adotado o critério de menor preço, observados os prazos máximos para fornecimento, as especificações técnicas e parâmetros mínimos de desempenho e qualidade definidos no edital;

\subsubsection{Lei 12.462/2011}

Institui o Regime Diferenciado de Contratações Públicas - RDC aplicável exclusivamente às licitações e contratos necessários à realização:

I - dos Jogos Olímpicos e Paraolímpicos de 2016, constantes da Carteira de Projetos Olímpicos a ser definida pela Autoridade Pública Olímpica (APO); e

II - da Copa das Confederações da Federação Internacional de Futebol Associação - Fifa 2013 e da Copa do Mundo Fifa 2014, definidos pelo Grupo Executivo - Gecopa 2014 do Comitê Gestor instituído para definir, aprovar e supervisionar as ações previstas no Plano Estratégico das Ações do Governo Brasileiro para a realização da Copa do Mundo Fifa 2014 - CGCOPA 2014, restringindo-se, no caso de obras públicas, às constantes da matriz de responsabilidades celebrada entre a União, Estados, Distrito Federal e Municípios;

III - de obras de infraestrutura e de contratação de serviços para os aeroportos das capitais dos Estados da Federação distantes até 350 $\mathrm{km}$ (trezentos e cinquenta quilômetros) das cidades sedes dos mundiais referidos nos incisos I e II.

IV - das ações integrantes do Programa de Aceleração do Crescimento (PAC) (Incluído pela Lei ${ }^{\circ} 12.688$, de 2012)

$\mathrm{V}$ - das obras e serviços de engenharia no âmbito do Sistema Único de Saúde - SUS. (Incluído pela Lei no 12.745, de 2012)

VI - das obras e serviços de engenharia para construção, ampliação e reforma e administração de estabelecimentos penais e de unidades de atendimento socioeducativo; (Incluído pela Lei ${ }^{\circ} 13.190$, de 2015)

VII - das ações no âmbito da segurança pública; (Incluído pela Lei $n^{\circ}$ 13.190, de 2015)

VIII - das obras e serviços de engenharia, relacionadas a melhorias na mobilidade urbana ou ampliação de infraestrutura logística; e (Incluído pela Lei $n^{\circ} 13.190$, de 2015)

IX - dos contratos a que se refere o art. 47-A. (Incluído pela Lei $n^{\circ}$ 13.190, de 2015)

$\mathrm{X}$ - das ações em órgãos e entidades dedicados à ciência, à tecnologia e à inovação. (Incluído pela Lei n 13.243 , de 2016) 
Conforme artigo $8^{\circ}$ da Lei $n^{0} 12.462 / 2011$, na execução indireta de obras e serviços de engenharia, são admitidos os seguintes regimes:

$$
\begin{aligned}
& \text { I - empreitada por preço unitário; } \\
& \text { II - empreitada por preço global; } \\
& \text { III - contratação por tarefa; } \\
& \text { IV - empreitada integral; ou } \\
& \text { V - contratação integrada. }
\end{aligned}
$$

Observou-se que nas contratações referentes às Instalações Portuária Públicas de Pequeno Porte, a contratação integrada foi o regime predominantemente utilizado. $O$ artigo $9^{\circ}$ da Lei $n^{\circ} 12.462$, indica em quais condições poderá ser utilizada, bem como define o seu conceito, vejamos:

Art. $9^{\circ}$ Nas licitações de obras e serviços de engenharia, no âmbito do $\mathrm{RDC}$, poderá ser utilizada a contratação integrada, desde que técnica e economicamente justificada e cujo objeto envolva, pelo menos, uma das seguintes condições: (Redação dada pela Lei $n^{\circ} 12.980$, de 2014) I - inovação tecnológica ou técnica; (Incluído pela Lei $\mathrm{n}^{\circ} 12.980$, de 2014)

II - possibilidade de execução com diferentes metodologias; ou (Incluído pela Lei $n^{\circ} 12.980$, de 2014)

III - possibilidade de execução com tecnologias de domínio restrito no mercado. (Incluído pela Lei $\mathrm{n}^{\circ} 12.980$, de 2014)

$\S 1^{\circ} \mathrm{A}$ contratação integrada compreende a elaboração e o desenvolvimento dos projetos básico e executivo, a execução de obras e serviços de engenharia, a montagem, a realização de testes, a pré-operação e todas as demais operações necessárias e suficientes para a entrega final do objeto.

(...)

\section{PROCEDIMENTOS METODOLÓGICOS}

Como indicado na introdução deste artigo, seu objetivo geral é analisar as contratações de serviços e obras referente as Instalações Portuárias Públicas de Pequeno Porte - IP4 feitas pelo Departamento Nacional de Infraestrutura de Transportes - DNIT.

Inicialmente, foram identificadas as licitações realizadas pelo DNIT que envolviam as Instalações Portuárias Públicas de Pequeno Porte - IP4.

A partir desses achados, a segunda parte da pesquisa se dirige a destacar questões como estas: quantidade de participantes, percentual de desconto e taxa de sucesso em cada modalidade ou lei utilizada na contratação.

Com o resultado das análises pretende-se responder à seguinte questão: Qual modalidade adotada obteve maior êxito na contratação sob o viés da isonomia, vantajosidade e promoção do desenvolvimento nacional sustentável?

\section{RESULTADOS}

No ano de 2012, o DNIT publicou o edital $n^{\circ} 687 / 2012-00$, na modalidade Tomada de Preços, visando a contratação dos projetos básico e executivos para construção de IP4 no município de Guajará-Mirim. Entretanto, com a publicação da 
Medida Provisória $n^{\circ}$ 595, de 06 de dezembro de 2012, o edital fora revogado, uma vez que as competências referentes à portos fluviais e lacustres foram transferidas à Secretária de Portos da Presidência da República.

Com o advento da Lei $\mathrm{n}^{\circ} 12.815$ de 2013, a competência relativa às Instalações Portuárias Públicas de Pequeno Porte retornou ao DNIT, conforme artigo 65, in litteris:

Art. 65. Ficam transferidas à Secretaria de Portos da Presidência da República as competências atribuídas ao Ministério dos Transportes e ao Departamento Nacional de Infraestrutura de Transportes - DNIT em leis gerais e específicas relativas a portos fluviais e lacustres, exceto as competências relativas a instalações portuárias públicas de pequeno porte. (grifo nosso)

Diante deste marco legislatório, no ano de 2014, o DNIT publicou o Edital $n^{\circ}$ 014/2014-02, que tinha como regime de execução, a contratação integrada (RDCi), que poderia ser utilizada, desde que técnica e economicamente justificada, sob jurisdição da Superintendência Regional do DNIT no Estado do Pará, visando a execução dos Projetos Básico e Executivo e Construção do IP4 nos municípios de São Miguel do Guamá, Augusto Corrêa e Viseu.

O certame tinha como modalidade o Regime Diferenciado de Contratações Públicas, uma vez que tal empreendimento era uma ação integrante do Programa de Aceleração do Crescimento (PAC), portanto, plenamente cabível sua utilização.

No tocante à contratação de Portos, o PAC visa a ampliação, recuperação e modernização das estruturas nos portos brasileiros, garantindo a melhoria da eficiência operacional, aumento da competitividade, e incentivo ao investimento privado. (Brasil, 2019)

Diante das especificidades inerentes ao regime integrado de contratação, apenas 2 (duas) licitantes participaram do RDC, que obteve $10,43 \%$ de desconto.

De 2014 até 2017 foram publicadas 17 (dezessete) licitações na modalidade RDCi. Destas, apenas 7 (sete) foram homologadas, demonstrando uma das dificuldades encontradas na contratação integrada de obras relacionadas à IP4.

A partir de novembro de 2014, fora publicado o edital $n^{\circ} 580 / 2014-01$, sob jurisdição da Superintendência Regional do DNIT no Estado do Amazonas, que objetivava a contratação das Obras Remanescentes da Instalação Portuária, na modalidade tomada de preços, que deveria ser utilizada no caso de obras e serviços de engenharia cuja contratação não ultrapassasse o valor de $\mathrm{R} \$ 1.500 .000,00$ (um milhão e quinhentos mil reais).

No entanto, o edital $n^{\circ} 580 / 2014-01$, restou fracassado, uma vez que o único licitante participante foi inabilitado. As demais licitações publicadas no ano de 2014, na modalidade Tomada de Preços foram revogadas com o entendimento que o objeto em questão se encaixava no conceito de serviço comum de engenharia, ou seja, poderia ser contratado na modalidade pregão.

Posteriormente, foram publicados os Editais $n^{\circ} 703 / 2014-01$ e $n^{0} 808 / 2014-01$, sob jurisdição da Superintendência Regional do DNIT no Estado do Amazonas, para contratação dos serviços remanescentes para instalação do IP4 nos municípios de Nhamundá e Maué, respectivamente. Estes editais foram publicados sob a modalidade Pregão, tendo em vista a Súmula nº 257/2010 do Tribunal de Contas da União:

Súmula 257 - TCU: O uso do pregão nas contratações de serviços comuns de engenharia encontra amparo na Lei 10.520/2002. 
Interessante ressaltar que de 2014 até o ano de 2018 foram publicadas 18 (dezoito) licitações na modalidade pregão, visando a contratação de projetos, serviços remanescentes e de instalações referentes à IP4.

Faz-se necessário neste momento adentrar em um pequeno histórico de todas as contratações realizadas pelo DNIT, para que se possa atingir o objetivo deste trabalho.

Após a publicação da Lei $n^{\circ} 12.815$ de 2013, o Departamento Nacional de Infraestrutura de Transportes publicou 54 (cinquenta e quatro) licitações de obras e serviços de engenharia relacionadas às Instalações Portuárias Públicas de Pequeno Porte. Destas 54 (cinquenta e quatro), 21 (vinte e uma) licitações referem-se à obras de engenharia, e 33 (trinta e três) referem-se à serviços de engenharia.

Desde então, 29 (vinte e nove) licitações foram homologadas, totalizando 43 (quarenta e três) lotes homologados, que perfazem o valor total de $\mathrm{R} \$ 230.934 .505,99$ (duzentos e trinta milhões, novecentos e trinta e quatro mil e noventa e nove centavos), e desconto total de $\mathrm{R} \$ 17.246 .429,56$ (dezessete milhões, duzentos e quarenta e seis mil, quatrocentos e vinte e nove reais e cinquenta e seis centavos).

Verificou-se que o sucesso das licitações, bem como os descontos obtidos evoluíram com o passar dos anos, fator que pode estar ligado com o crescimento da média de licitantes participantes nos certames. A tabela 01 , demonstra 0 aproveitamento das licitações, durante os anos.

Tabela 01: Licitações realizadas anualmente no DNIT referente aos IP4.

\begin{tabular}{|c|c|c|c|c|c|c|}
\hline Ano & Homologadas & $\begin{array}{c}\text { Fracassadas/ } \\
\text { Revogadas }\end{array}$ & Total & $\begin{array}{c}\text { Média de } \\
\text { Licitantes }\end{array}$ & $\begin{array}{c}\text { Desconto } \\
\text { médio }\end{array}$ & Sucesso (\%) \\
\hline 2012 & 0 & 1 & 1 & 0 & 0 & $0 \%$ \\
\hline 2014 & 8 & 16 & 24 & 2,2 & $6,5 \%$ & $33 \%$ \\
\hline 2015 & 11 & 7 & 18 & 8,9 & $2,4 \%$ & $58 \%$ \\
\hline 2016 & 4 & 0 & 4 & 10,2 & $12,27 \%$ & $100 \%$ \\
\hline 2017 & 1 & 1 & 2 & 3 & $5,6 \%$ & $66 \%$ \\
\hline 2018 & 5 & 0 & 5 & 9,7 & $33,4 \%$ & $100 \%$ \\
\hline
\end{tabular}

A tabela 02, corrobora o entendimento de que o aproveitamento da licitação está intrinsicamente ligado ao número de licitantes, bem como à modalidade utilizada.

Tabela 02: Licitações realizadas no DNIT referente aos IP4 divididas por modalidade e critério de julgamento.

\begin{tabular}{|c|c|c|c|c|c|c|}
\hline $\begin{array}{c}\text { Modalidade/ } \\
\text { Critério de } \\
\text { julgamento }\end{array}$ & Homologadas & $\begin{array}{c}\text { Fracassadas/ } \\
\text { Revogadas }\end{array}$ & Total & $\begin{array}{c}\text { Desconto } \\
\text { médio }\end{array}$ & $\begin{array}{c}\text { Média de } \\
\text { Licitantes }\end{array}$ & $\begin{array}{c}\text { Sucesso } \\
\text { (\%) }\end{array}$ \\
\hline $\begin{array}{c}\text { Tomada de } \\
\text { Preço/ } \\
\text { Menor Preço }\end{array}$ & 0 & 1 & 1 & 0 & 0 & $0 \%$ \\
\hline $\begin{array}{c}\text { Tomada de } \\
\text { Preço/ } \\
\text { Técnica e } \\
\text { Preço }\end{array}$ & 0 & 7 & 7 & 0 & 0 & $0 \%$ \\
\hline $\begin{array}{c}\text { RDC/ Menor } \\
\text { Preço }\end{array}$ & 4 & 6 & 10 & $3,12 \%$ & 8,25 & $40 \%$ \\
\hline $\begin{array}{c}\text { RDC/ Maior } \\
\text { Desconto }\end{array}$ & 6 & 1 & 7 & $1,85 \%$ & 4,6 & $85 \%$ \\
\hline
\end{tabular}




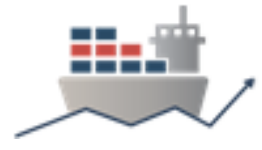

\begin{tabular}{|c|c|c|c|c|c|c|}
\hline $\begin{array}{c}\mathrm{RDC} / \\
\text { Técnica e } \\
\text { Preço }\end{array}$ & 5 & 6 & 11 & $9,25 \%$ & 1,57 & $45 \%$ \\
\hline $\begin{array}{c}\text { Pregão/ } \\
\text { Menor Preço }\end{array}$ & 14 & 4 & 18 & $16,02 \%$ & 9,5 & $77 \%$ \\
\hline
\end{tabular}

Como pode ser observado, as licitações na modalidade Pregão obtiveram em média 9,5 licitantes, consequentemente o desconto médio de $16,02 \%$ foi o maior dentre as modalidades escolhidas para contratações referentes à IP4.

No entanto, as licitações na modalidade RDC Maior Desconto, obtiveram o maior índice de aproveitamento, uma vez que $85 \%$ das licitações publicadas foram homologadas.

Importante ressaltar que as licitações na modalidade RDC, considerando os três critérios de julgamento (menor preço, técnica e preço e maior desconto) obtiveram um percentual médio de apenas $6 \%$ de desconto. Este item pode ser explicado pelo fato de que 7 (sete) das 15 (quinze) licitações que foram homologadas tratavam-se de contratação integrada, portanto objeto mais complexo, uma vez que as licitantes devem ter experiência prévia em elaboração de projetos e a construção de IP4.

Em contrapartida, é interessante comparar serviços de igual complexidade, que foram licitados em diferentes modalidades. Este comparativo pode ser observado na Tabela 03.

Tabela 03: Licitações realizadas no DNIT referente aos IP4 divididas por modalidade e objeto similar.

\begin{tabular}{|c|c|c|c|c|c|c|}
\hline $\begin{array}{c}\text { Modalidade/ } \\
\text { Objeto }\end{array}$ & Homologadas & $\begin{array}{c}\text { Fracassadas/ } \\
\text { Revogadas }\end{array}$ & Total & Sucesso(\%) & $\begin{array}{c}\text { Média de } \\
\text { licitantes }\end{array}$ & $\begin{array}{c}\text { Desconto } \\
\text { Médio (\%) }\end{array}$ \\
\hline RDC/ Obra & 11 & 10 & 21 & $52 \%$ & 6,3 & $4,52 \%$ \\
\hline RDC/ Serviço & 4 & 3 & 7 & $57 \%$ & 3,7 & $5,55 \%$ \\
\hline $\begin{array}{c}\text { Tomada de } \\
\text { Preços/ } \\
\text { Serviço }\end{array}$ & 0 & 8 & 8 & $0 \%$ & 1 & 0 \\
\hline $\begin{array}{c}\text { Pregão/ } \\
\text { Serviço }\end{array}$ & 12 & 4 & 18 & $66 \%$ & 9,4 & $16 \%$ \\
\hline
\end{tabular}

Assim, pode ser verificado que mesmo na contratação de serviços de engenharia, que envolvem objetos menos complexos relacionados à IP4, a modalidade RDC indica um menor percentual de desconto.

Enquanto as licitações realizadas na modalidade Pregão para contratação de serviços de engenharia obtiveram um percentual médio de $16 \%$ de desconto, as licitações na modalidade RDC para contratação dos mesmos objetos, obtiveram um percentual médio de $5,55 \%$ de desconto.

Outro ponto interessante, refere-se ao fato de que a licitante Antonelly Construções e Serviços de Engenharia foi a vencedora em $41 \%$ das licitações homologadas pelo DNIT. Tal fator demonstra que as contratações referentes à IP4 encontram diversas dificuldades, uma delas é o mercado restrito à poucas empresas.

\section{CONCLUSÕES}

O objetivo geral deste artigo, foi analisar as contratações referentes à IP4 realizadas no âmbito do DNIT, sendo demonstrado nos resultados obtidos acima. 
O objetivo específico, foi indicar qual modalidade adotada nas licitações realizadas pelo DNIT, referentes à IP4, obteve maior êxito na contratação sob o viés da isonomia, vantajosidade e promoção do desenvolvimento nacional sustentável.

Inicialmente cumpre destacar o artigo $3^{\circ}$ da Lei $n^{\circ} 8.666 / 93$, onde indica que a licitação destina-se a garantir a isonomia, a seleção da proposta mais vantajosa, bem como a promoção do desenvolvimento nacional sustentável. Vejamos o inteiro teor, deste ditame legal:

Art. $3^{\circ}$ A licitação destina-se a garantir a observância do princípio constitucional da isonomia, a seleção da proposta mais vantajosa para a Administração e a promoção do desenvolvimento sustentável e será processada e julgada em estrita conformidade com os princípios básicos da legalidade, da impessoalidade, da moralidade, da igualdade, da publicidade, da probidade administrativa, da vinculação ao instrumento convocatório, do julgamento objetivo e dos que lhes são correlatos.

O princípio da isonomia visa garantir aos licitantes tratamento uniforme no decorrer do certame licitatório, razão pela qual a Administração deverá definir no instrumento convocatório, os critérios objetivos para escolha de seu contratado.

Para Marçal Justen Filho (2014, p.68), a isonomia significa o tratamento uniforme para situações uniformes, distinguindo-se-as na medida em que exista diferença. Desta forma, podemos concluir que objetos mais complexos devem restringir a participação de licitantes na medida de sua complexidade. Por outro lado, licitações que visam a contratação de objetos menos complexos, devem ter critérios restritivos proporcionais à garantia de execução do objeto.

Pode-se concluir, portanto, que licitações que visam a contratação de objetos mais complexos, possuem um mercado mais restrito, e consequentemente menores índices de licitantes. De modo contrário, as contratações menos complexas, naturalmente indicarão maior índice de participação.

Desta forma, quando comparamos a contratação de objetos de igual complexidade, o Pregão, enquanto modalidade, demonstra certa vantagem em detrimento à Tomada de Preços e RDC.

Conforme a Tabela 3, para a contratação de serviços de engenharia, ou seja, de menor complexidade, o percentual de licitantes que participaram nas licitações de modalidade Pregão foi de 9,4 enquanto que no RDC esta média foi de 3,7 e na Tomada de Preços, a média era de apenas 1 licitante.

Corroborando para o entendimento, uma pequena comparação de certames cujo objetos eram similares. O Edital $n^{\circ} 580 / 14-01$, publicado na modalidade Tomada de Preços, cujo objeto era a contratação da execução de obras remanescentes da IP4 de Maués/AM, teve a participação de apenas $1(\mathrm{um})$ licitante, enquanto o edital $n^{\circ}$ 466/16-01, publicado na modalidade Pregão, que tinha como objeto a contratação da execução de serviços remanescentes e reforma da IP4 de Benjamin Constant, teve a participação de 11 (onze) licitantes e finalmente, o edital $n^{\circ}$ 213/18-01, publicado na modalidade RDC, tendo como objeto a execução de serviços remanescentes e reforma da IP4 de Apuí/AM, teve a participação de 6 (seis) licitantes.

Como conclusão, para a contratação de serviços de engenharia relacionados à IP4, o Pregão é a modalidade mais adequada sob o viés da isonomia, tendo em vista que garante a maior participação de licitantes em seus certames.

O segundo objetivo da licitação é garantir a proposta mais vantajosa, caracterizando-se pelo seguinte: 


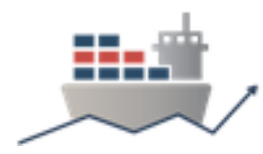

A vantagem caracteriza-se como a adequação e satisfação do interesse coletivo por via da execução do contrato. A maior vantagem possível configura-se pela conjugação de dois aspectos interrelacionais. Um dos ângulos relaciona-se com a prestação a ser executada por parte da Administração; o outro vincula-se à prestação a cargo do particular. A maior vantagem apresenta-se quando a Administração assumir o dever de realizar a prestação menos onerosa e o particular se obrigar a realizar a melhor e mais completa prestação. Configura-se, portanto, uma relação custo-benefício. A maior vantagem corresponde à situação de menor custo e maior benefício para a Administração. (Grifo nosso) (FILHO, 2014, p. 71)

Sob o viés da vantajosidade, tem-se que a licitação deve garantir a contratação de maneira menos onerosa para a Administração, e finalmente a execução do objeto por parte da contratada.

Diante de todo o histórico das contratações realizadas pelo DNIT, verifica-se que as licitações realizadas sob à égide do Pregão apresentaram maiores percentuais de descontos.

Entretanto, é sabido que a proposta mais vantajosa não necessariamente é aquela que apresentou menor desconto, e sim aquela que garante a execução do objeto contratado, aliada ao menor ônus para a Administração.

Como exemplo, no dia 08 de junho de 2018, foi veiculada notícia da inauguração da Instalação Portuária Pública de Pequeno Porte no município de Nhamundá, portanto, verifica-se o sucesso da contratação. Coincidentemente, verificou-se que o edital $n^{\circ}$ 232/16-01, que visava a execução da reforma e ampliação da IP4 de Nhamundá, foi realizada sob a modalidade Pregão, com 12 licitantes e percentual de desconto na licitação de 5,01\% conforme figura 03 .

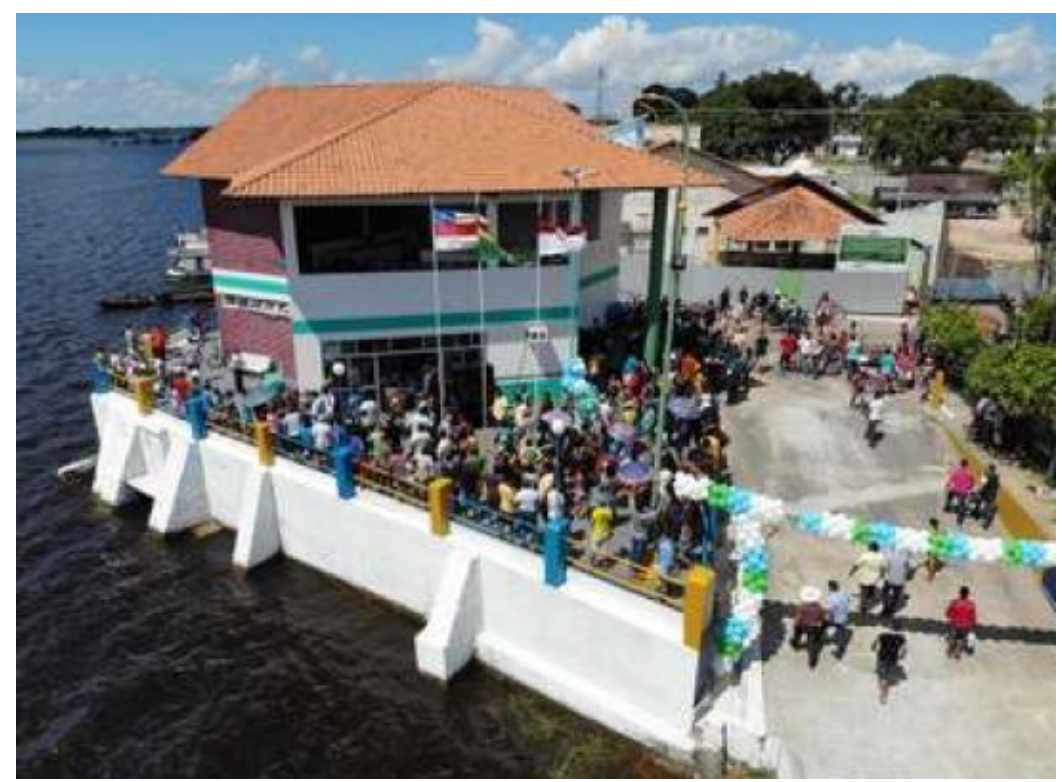

Figura 03: Inauguração da Instalação Portuária Pública de Pequeno Porte no município de Nhamundá. Fonte: Ministério da Infraestrutura

Como conclusão, para a contratação de serviços de engenharia relacionados à IP4, o Pregão é a modalidade mais adequada sob o viés da vantajosidade, uma vez que garante os maiores descontos, aliados à fiel execução do contrato. 
O terceiro e último viés ao qual este trabalho busca analisar, refere-se à garantia do desenvolvimento nacional sustentável, que visa garantir sob a ótica da dignidade humana, o desenvolvimento da qualidade de vida dos brasileiros.

As Instalações Portuárias Públicas de Pequeno Porte em sua essência, visam garantir melhores condições de vida às populações que dependem do fornecimento de medicamentos, alimentos, vestimentas, dentre outros itens básicos. Desta forma, o sucesso da licitação é essencial para o desenvolvimento dos municípios e consequentemente de sua população.

Furtado (2016) indica que a infraestrutura da IP4 aumenta as chances dos municípios se destacarem economicamente, uma vez que se tornam atrativas às empresas, à medida que proporcionam uma maior eficiência com menor tempo de espera das embarcações, com rapidez no embarque e desembarque de passageiros e cargas, pelo menor preço possível.

Conclui-se, portanto, que o índice de aproveitamento da licitação garante o maior desenvolvimento nacional, uma vez que o sucesso da contratação é indicativo de garantia das necessidades da população. Neste aspecto, observa-se que as licitações realizadas sob a égide do Pregão obtiveram um índice de $66 \%$ de sucesso, o maior dentre as demais modalidades.

Portanto, para a contratação de serviços de engenharia relacionados à IP4, o Pregão é a modalidade mais adequada sob o viés do desenvolvimento nacional sustentável, uma vez que dentre as modalidades, obteve a maior taxa de aproveitamento.

Interessante destacar que em $100 \%$ das licitações homologadas no estado do Pará e 68\% das licitações homologadas no estado do Amazonas, o licitante vencedor possui sede no próprio local da contratação, indicando grandes possibilidades de fomento à economia local, e consequente desenvolvimento nacional.

Esta média indica conformidade com os percentuais gerais de licitações, uma vez que conforme dados do Infográfico realizado pelo Negócios Públicos, nos Estados do Amazonas e Pará, em 53,9\% e 55,2\% dos Pregões Eletrônicos realizados, os vencedores possuem sede na mesma unidade federativa da contratação, conforme figura 04.

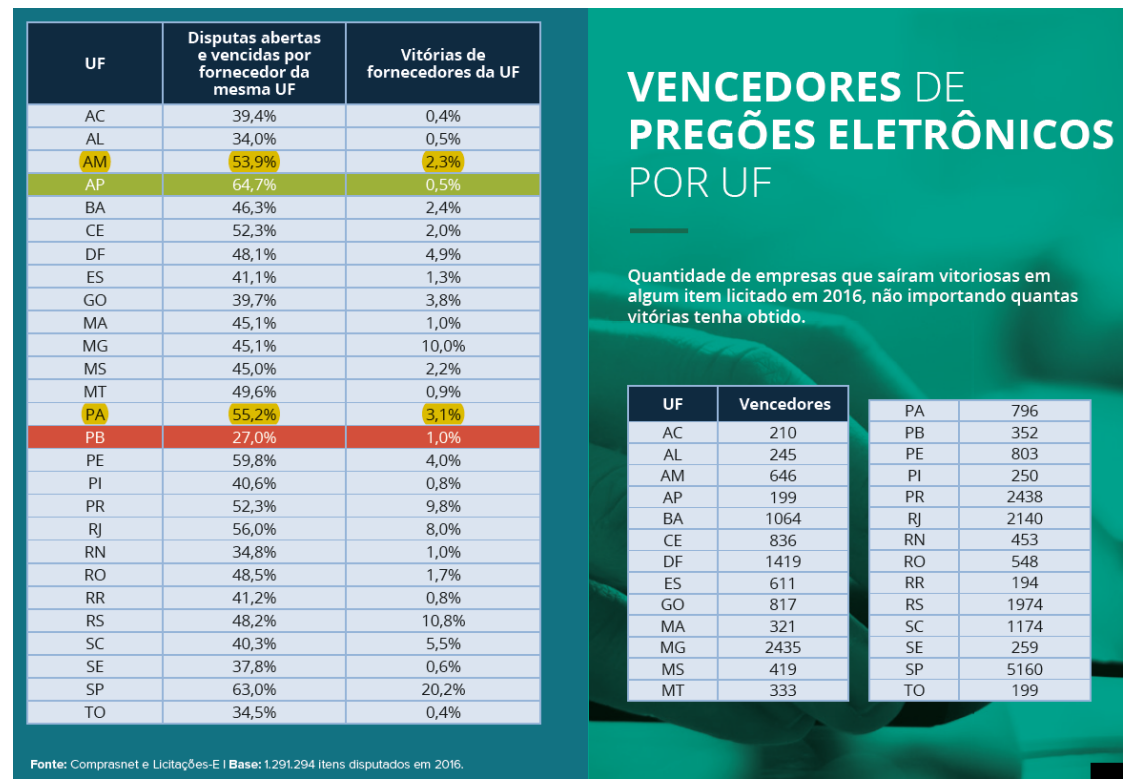

Figura 04: Infográficos - Informativo do Instituto Negócios Públicos. Edição de 2017. 


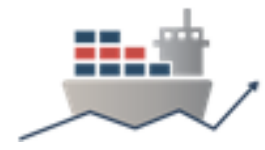

Imperioso ressaltar que em $68 \%$ das licitações eletrônicas homologadas, o licitante vencedor possui sede no próprio local da contratação.

Outro destaque deve-se ao fato que as contratações referentes à IP4 demonstraram maior vantagem para a Administração quando realizadas no modo eletrônico, como pode ser demonstrado na tabela 04:

Tabela 04: Licitações realizadas no DNIT referente aos IP4 divididas por modo.

\begin{tabular}{|c|c|c|c|c|c|c|}
\hline Modo & Homologadas & $\begin{array}{c}\text { Fracassadas/ } \\
\text { Revogadas }\end{array}$ & Total & $\begin{array}{c}\text { Sucesso } \\
\mathbf{( \% )}\end{array}$ & $\begin{array}{c}\text { Média } \\
\text { de } \\
\text { Licitantes }\end{array}$ & $\begin{array}{c}\text { Média } \\
\text { de } \\
\text { Desconto }\end{array}$ \\
\hline Presencial & 4 & 14 & 18 & $22 \%$ & 1,25 & $10,9 \%$ \\
\hline Eletrônica & 25 & 11 & 36 & $69 \%$ & 8,14 & $10,83 \%$ \\
\hline
\end{tabular}

Verifica-se que as licitações eletrônicas obtiveram maior taxa de sucesso e maior média de licitantes, demonstrando vantagem sob o viés da promoção do desenvolvimento sustentável e da isonomia em detrimento à licitação presencial.

Desta forma, escolhas mais eficientes, trazem vantagens ao processo contratual das Instalações Portuárias Públicas de Pequeno Porte, ampliando a utilização do modal aquaviário e do desenvolvimento nacional. Conforme demonstra Alexandre Lobo, o transporte aquaviário representa um percentual de $50 \%$ na China, sendo necessário que o Brasil busque melhorias nesse sentido, vejamos:

$\mathrm{Na}$ matriz de transportes apresentada pelo ILOS recentemente no Fórum Internacional de Supply Chain, o Brasil conta, atualmente, com apenas $21 \%$ da produção passando pelas ferrovias nacionais, enquanto o transporte aquaviário movimenta em torno de $13 \%$ das cargas. Em contrapartida, na China, mais de $50 \%$ da produção é escoada pelo modal aquaviário e, nos Estados Unidos, $30 \%$ das cargas passam pela ferrovia. Ou seja, muito trabalho, e investimento, ainda precisa ser realizado no Brasil para melhorar a competitividade dos nossos produtos no mercado internacional. (Lobo, 2017)

Conclui-se, portanto, que a pesquisa realizada servirá como ponto de partida na escolha dos gestores públicos, tendo em vista que o planejamento da contratação e escolha da modalidade licitatória para contratação de IP4, impacta na execução contratual, acarretando consequentes melhorias no modal aquaviário brasileiro.

\section{REFERÊNCIAS}

1. BRASIL. Departamento Nacional de Infraestrutura de Transportes. Brasília, DF. Disponível em: http://www.dnit.gov.br/. Acesso em 20/08/2019.

2. BRASIL. Lei $n^{\circ} 8.666$ de 21 de junho de 1993. Regulamenta o art. 37, inciso XXI, da Constituição Federal, institui normas para licitações e contratos da Administração Pública e dá outras providências. Brasília, DF, jun,1993.

3. BRASIL. Lei $n^{\circ} 10.233$ de 5 de junho de 2001. Dispõe sobre a reestruturação dos transportes aquaviário e terrestre, cria o Conselho Nacional de Integração de Políticas de Transporte, a Agência Nacional de Transportes Terrestres, a Agência Nacional de Transportes Aquaviários e o Departamento Nacional de Infra-Estrutura de Transportes, e dá outras providências. Brasília, DF, jun. 2001. 


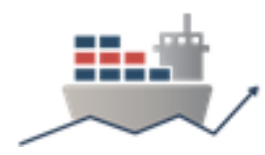

4. BRASIL. Lei $n^{\circ} 10.520$ de 17 de julho de 2002. Institui, no âmbito da União, Estados, Distrito Federal e Municípios, nos termos do art. 37, inciso XXI, da Constituição Federal, modalidade de licitação denominada pregão, para aquisição de bens e serviços comuns, e dá outras providências. Brasília, DF, jul. 2002.

5. BRASIL. Lei $n^{0} 12.815$ de 5 de junho de 2013. Dispõe sobre a exploração direta e indireta pela União de portos e instalações portuárias e sobre as atividades desempenhadas pelos operadores portuários, Brasília, DF, jun, 2013.

6. BRASIL. Lei $n^{\circ} 12.462$ de 4 de agosto de 2011. Institui o Regime Diferenciado de Contratações Públicas - RDC, Brasília, DF, ago. 2011.

7. BRASIL. Medida Provisória $n^{\circ} 595$ de 6 de dezembro de 2012. Dispõe sobre a exploração direta e indireta, pela União, de portos e instalações portuárias e sobre as atividades desempenhadas pelos operadores portuários, e dá outras providências. Brasília, DF, dez. 2011.

8. BRASIL. Ministério da Economia. Portos. Disponível em: http://www.pac.gov.br/infraestrutura-logistica/portos. Acesso em: 20/08/2019.

9. BRASIL. Ministério da Infraestrutura. DNIT inaugura Instalação Portuária de Pequeno Porte (IP4) em município do Amazonas. Disponível em: http://canaldoservidor.transportes.gov.br/curtas-do-mtpa/7176-dnit-inaugurainstala\%C3\%A7\%C3\%A3o-portu\%C3\%A1ria-de-pequeno-porte-ip4-emmunic\%C3\%ADpio-do-amazonas.html. Acesso em: 19/08/2019.

10. BRASIL. Portal de Compras do Governo Federal. Disponível em: https://www.comprasgovernamentais.gov.br. Acesso em: 20/08/2019

11. BRASIL. Tribunal de Contas da União. Acórdão no 1167/2014 - Plenário. Processo $\mathrm{n}^{\circ}$ 029.394/2016-9. Relator: José Múcio Monteiro. Disponível em: https://pesquisa.apps.tcu.gov.br/\#/documento/acordaocompleto/*/NUMACORDAO\%253A1167\%2520ANOACORDAO\%253A2014/DTRELE VANCIA\%20desc,\%20NUMACORDAOINT\%20desc/0/\%20?uuid=4a4c1720-c38811e9-9bda-6b4db153d5e4. Acesso em 20/08/2019.

12. BRASIL. Tribunal de Contas da União. Súmula $n^{\circ} 257$. O uso do pregão nas contratações de serviços comuns de engenharia encontra amparo na Lei 10.520/2002. Brasília, DF. Disponível em: https://pesquisa.apps.tcu.gov.br/\#/documento/sumula/\%252a/NUMERO\%253A257/D TRELEVANCIA\%2520desc/0/sinonimos\%3Dfalse. Acesso em 20/08/2019

13. DEPARTAMENTO NACIONAL DE INFRAESTRUTURA DE TRANSPORTES. Aprova o Regimento Interno do Departamento Nacional de Infraestrutura de Transportes - DNIT, objeto do processo $n^{\circ}$. 50600.012271/2015-10. Resolução $n^{\circ}$ 26 de 5 de maio de 2016.

14. FERNANDES, Jorge Ulisses Jacoby. Portos Legislação. 1 ed. Belo Horizonte: Fórum, 2016.

15. FILHO, Marçal Justen. Comentários à lei de Licitações e Contratos Administrativos. 16. ed. São Paulo: Revista dos Tribunais, 2014. 
VI CIDESPORT/2019

Congresso Internacional

de Desempenho Portuário

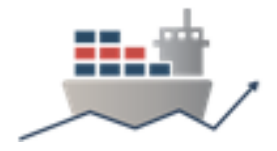

16. FURTADO, Carlos Gilmar Nascimento; KZAN, Andressa Cardoso; MORAES, Rita de Cássia Monteiro de. A IMPORTÂNCIA DAS INSTALAÇÕES PORTUÁRIAS PÚBLICAS DE PEQUENO PORTE (IP4) PARA AUXILIAR NO DESENVOLVIMENTO DOS MUNICÍPIOS DO PARÁ. In: Anais da VII Mostra de Pesquisa em Ciência e Tecnologia DeVry Brasil. Anais... BELÉM, CARUARU, FORTALEZA, JOÃO PESSOA, MANAUS, RECIFE, SALVADOR, SÃO LUÍS, SÃO PAULO, TERESINA: DEVRY BRASIL, 2016. Disponível em: https://www.even3.com.br/anais/viimostradevry/29776-a-importancia-dasinstalacoes-portuarias-publicas-de-pequeno-porte-(ip4)-para-auxiliar-nodesenvolvimento-dos-municipios-do-para/. Acesso em: 20/08/2019.

17. Instituto Negócios Públicos do Brasil. Infográficos: Informativo do Instituto Negócios Públicos, Compras Públicas. Curitiba, 2017.

18. LOBO, Alexandre. Transporte de cargas e a encruzilhada do Brasil para o futuro, 08/11/2017. Disponível em: https://www.ilos.com.br/web/transporte-de-cargas-e-aencruzilhada-do-brasil-para-o-futuro/. Acesso em 20/08/2019.

19. MOREIRA, André Cavalcante. Administrações Hidroviárias, 26/12/2018. Disponível em: https://www.dnit.gov.br/modais-2/aquaviario/administracoeshidroviarias. Acesso em 06/08/2019.

20. MOREIRA, André Cavalcante. Instalações Portuárias Públicas de Pequeno Porte - IP4, 26/12/2018. Disponível em: http://www.dnit.gov.br/modais2/aquaviario/ip4/instalacoes-portuarias-publicas-de-pequeno-porte-2013-ip4. Acesso em 06/08/2019. 